\title{
PERANCANGAN SISTEM INFORMASI PENJUALAN PADA TOKO MINAK SINGA
}

\author{
Sri Ipnuwati \\ Program Studi Sistem Informasi \\ STMIK Pringsewu Lampung \\ Jl.Wisma Rini No.09 Pringsewu Telp/Fax. (0729) 22240.www.stmikpringsewu.ac.id \\ E-mail : nengachie@gmail.com \\ Handphone : 087877127901
}

\begin{abstract}
Abstrak
Persaingan penjualan di Desa Kedondong Kabupaten Pesawaran Provinsi Lampung semakin ketat, Toko Minak Singa adalah salah satu Toko yang telah berdiri sejak tahun 2010 di Desa Kedondong Kabupaten Pesawaran Provinsi Lampung. Mekanisme sistem penjualan sekarang masih menggunakan sistem konvensional, dimana konsumen harus datang langsung ke outlet atau melalui sales marketing. Dengan adanya Sistem Informasi pada Toko Minak Singa diharapkan dapat memberikan kemudahan kepada masyarakat untuk melakukan pembelian produk tanpa harus datang ke tempatnya, serta memperluas pemasaran dan meningkatkan costumer loyality. Usaha ini dikembangkan dengan SDLC (System Development Life Cycle) dan software yang digunakan untuk merancang dan mendesain Aplikasi yaitu bahasa pemrograman PHP dan Database MySQL. Aplikasi ini juga dapat menghasilkan informasi produk yang dijual, serta menyajikan laporan-laporan yang ditujukan kepada pemilik (owner) diantaranya: laporan produk, laporan outlet, laporan order, dan laporan penjualan.
\end{abstract}

Kata Kunci : Perancangan, Sistem Informasi, PHP, MySQL.

\section{PENDAHULUAN}

\subsection{Latar Belakang Masalah}

Sejalan dengan cepatnya perkembangan bidang teknologi, Penggunaan internet yang menjurus kepada cyberspace kelihatannya akan mendominasi seluruh kegiatan di atas permukaan bumi di masa kini dan masa datang. Secara umum akan berubah menjadi alat untuk persaingan antara perusahaan yang satu dengan yang lainnya. Evolusi yang terjadi pada internet merupakan satu fenomena yang paling menarik dalam kemajuan teknologi yang terjadi sekarang. Sektor bisnis merupakan sektor yang paling terkena dampak dari perkembangan teknologi informasi dan telekomunikasi. Melalui E-commerce dapat memiliki peluang yang sama agar dapat bersaing dan berhasil berbisnis di dunia maya. E-commerce (electronic commerce) akhir-akhir ini telah marak dengan munculnya ribuan perusahaan yang menawarkan barang dagangannya di dalam website. Lebih dari $80 \%$ perusahaan yang masuk dalam Fortune 500 memiliki web site di Internet.

E-commerce adalah kegiatan-kegiatan bisnis dengan tujuan mengambil keuntungan seperti penjualan, pembelian, pelayanan, informasi, dan perdagangan melalui perantara yaitu melalui suatu jaringan komputer, terutama internet. Dengan adanya E-commerce ini memudahkan costumer untuk dapat melakukan transaksi jual beli tanpa harus datang ke tempatnya.

Manfaat dari penerapan penggunaan E-commerce, akan memberikan gambaran tentang bagaimana tehnik sistem penjualan yang dibutuhkan dalam menghadapi persaingan perusahaan di era globalisasi saat ini. Diharapkan mampu memudahkan bagi penjual dalam membuat laporan rekapitulasi penjualan sehingga laporan dapat dihasilkan dengan cepat dan akurat. Dalam penelitian ini, obyek penelitian adalah Toko Minak Singa yang merupakan sebuah usaha dagang yang bergerak di bidang penjualan makanan, yang 
terletak di Jalan Pasar Lama Kedondong Kabupaten Pesawaran Provinsi Lampung. Toko Minak Singa itu sendiri merupakan salah satu usaha perseorangan (Owner) yang menawarkan berbagai macam produk makanan. Produk yang ditawarkan seperti Nugget berbagai merk, Baso ikan dan baso sapi, Sosis ayam dan Sosis sapi, Burger dan berbagai makanan beku lainnya. Dalam memasarkan produk tersebut, sasaran pangsa pasar disini cenderung pada anak-anak usia sekolah (7th - 15th). Toko Minak Singa mempunyai daya tarik sendiri yaitu mampu memasarkan produk-produk terbarunya setiap ada produk baru dengan mengikuti alur dan trend selera masyarakat luas yang tidak punya cukup banyak waktu. Mekanisme Sistem penjualan yang dipakai pada Toko Minak Singa sekarang ini masih memakai sistem konvensional, yaitu pembeli yang harus datang langsung ke outlet atau melalui sales marketing sehingga dapat menyita waktu konsumen yang berada jauh dari outlet tersebut. Dikarenakan ketatnya persaingan harus bisa merespon hal-hal tersebut guna mencapai efiktifitas maupun efisiensi, memperluas daerah pemasaran serta meningkatkan costumer loyality. Berdasarkan latar belakang diatas, peneliti berupaya untuk memecahkan permasalahan tersebut, yaitu dengan mengangkat judul "Perancangan Sistem Informasi Penjualan pada Toko Minak Singa".

\subsection{Rumusan Masalah}

Terkait dengan pernyataan diatas, maka perumusan masalah sebagai berikut :

a. Bagaimana memberikan informasi mengenai penjualan yang ada pada Toko Minak Singa melalalui Web.

b. Bagaimana memberikan kemudahan konsumen untuk bertransaksi dan mengenal prodak yang akan dipasarkan.

\subsection{Tujuan Penelitian}

Tujuan dari penelitian ini adalah :

a. Untuk membuat rancangan aplikasi ECommerce berbasis Web menggunakan PHP dan MySQL pada studi kasus "Toko Minak Singa".

b. Untuk membuat suatu rancangan aplikasi ECommerce sehingga memudahkan konsumen untuk mendapatkan barang yang diinginkan tanpa harus datang langsung ke outlet serta mempermudah konsumen dalam melakukan proses transaksi secara online.

c. Memudahkan customer dalam mengetahui produk apa saja yang ditawarkan oleh Toko Minak Singa tanpa harus datang langsung ke outlet tersebut.

\subsection{Batasan Masalah}

a. Merancang Sistem Informasi penjualan barang (E-Commerce) pada Toko Minak Singa.

b. Perancangan Sistem Informasi ini hanya melakukan proses pembelian, persediaan, dan penjualan barang (barang masuk, stok barang dan barang keluar), layanan service dan laporan berdasarkan batasan tanggal bulan dan tahun.

c. Sistem Informasi Penjualan (E-Commerce) ini dibangun dengan menggunakan bahasa pemograman PHP dan Database MySQL sebagai olah datanya.

\subsection{Metode Penelitian}

Metode pengembangan sistem yang digunakan dalam pembuatan strategi web e-commerce ini adalah SDCL (system development life cycle):

\subsubsection{Perencanaan}

Pada tahap ini dilakukan pengenalan diagnosa dan mengidentifikasi masalah yang ada dan mencari alternatif pemecahannya.

\subsubsection{Analisis Sistem}

Mendefinisikan dan memahami kebutuhan software. Untuk mengetahui sifat dari program yang akan dibuat, seperti fungsi yang dibutuhkan, performansi (kemampuan) dan antarmuka yang dibutuhkan. Tahapan ini harus didokumentasikan dan ditunjukkan kepada pengguna sistem.

\subsubsection{Desain Sistem}

Tahap ini membuat desain aliran kerja manajemen dan desain pemrograman yang diperlukan untuk pengembangan sistem informasi serta memberikan 
gambaran yang jelas bagaimana suatu sistem dibentuk.

\subsubsection{Implementasi}

Setelah sistem baru telah dibuat maka diterapkan dalam kegiatan sehari - hari tanpa meninggalkan sistem lama supaya dapat dievaluasi dan dibandingkan dengan sistem lama.

\subsubsection{Evaluasi}

Pada tahap ini dilakukan evaluasi terhadap program baru apakah sudah sesuai dengan rencana atau masih perlu ada perubahan - perubahan yang diperlukan.

Analisis sistem dapat didefinisikan sebagai penguraian dari suatu sistem informasi yang utuh ke dalam bagian-bagian komponennya dengan maksud untuk mengidentifikasikan dan mengevaluasi permasalahan, kesempatan, hambatan yang terjadi dan kebutuhan yang diharapkan sehingga dapat diusulkan perbaikannya. Sedangkan perancangan dapat diartikan sebagai penggambaran, perencanaan dan pembuatan sketsa atau pengaturan dari beberapa elemen terpisah ke dalam suatu kesatuan utuh dan berfungsi.

\section{LANDASAN TEORI}

\subsection{Definisi Sistem}

Secara sederhana sistem dapat diartikan sebagai suatu kumpulan/himpunan dari unsur variabel yang terorganisir, saling berinteraksi, dan ketergantungan satu sama lain. Menurut Jogiyanto Hartono (2005:2), sistem adalah kumpulan dari elemen - elemen yang berinteraksi untuk mencapai suatu tujuan tertentu.Sistem memiliki beberapa pengertian yang pada dasarnya mempunyai satu tujuan. Berdasarkan pengertian diatas, dapat diketahui bahwa sistem adalah suatu jaringan kerja yang terdiri atas komponen - komponen atau elemen-elemen yang saling berinteraksi melalui tahapan - tahapan instruksi untuk menyelesaikan suatu kegiatan atau tujuan tertentu. Tujuan dari sistem yang dikembangkan adalah untuk memenuhi kebutuhan pemakai dan memberikan gambaran yang jelas tentang rancang bangun sistem kepada programmer dan ahli teknik lainnya.

\subsection{Definisi Informasi}

Ada beberapa pengertian informasi diantaranya: Menurut H.M. Yogianto dalam bukunya yang berjudul Analisis dan Desain Sistem Informasi Pendekatan Terstruktur pengertian informasi sebagai berikut: "informasi merupakan data yang telah diproses ke dalam suatu bentuk yang mempunyai arti bagi si penerima dan mempunyai nilai nyata serta terasa bagi keputusan saat itu atau keputusan yang akan datang."

Gordon B. Davis dalam bukunya yang berjudul Kerangka Dasar Sistem Informasi Manajemen memberikan pengertian informasi sebagai berikut: "Informasi adalah data yang telah diolah menjadi sebuah bentuk yang berguna dan nyata atau berupa nilai yang dapat dipahami dalam keputusan sekarang maupun yang akan datang."

\subsection{Definisi E-Commerce}

E-Commerce (Electronic Commerce) merupakan teknologi yang sedang berkembang sangat pesat, jaringan elektronik seperti internet. E-Commerce merupakan suatu cara berbelanja secara online, baik pembelian maupun penjualan barang dan jasa yang seiring dengan kehadirannya memudahkan kita dalam kehidupan sehari-hari. Banyak orang mendapatkan manfaat kemudahan berbisnis melalui media internet ini.

Menurut David Baum definisi E-commerce yang sudah di standartkan dan disepakati bersama adalah "E-commerce is a dynamic set of technologies, applications, and business process that link enterprise, consumers, and communities through electronic transactions and the electronic exchange of goods, services, and information". Ecommerce merupakan suatu set dinamis teknologi, aplikasi dan proses bisnis yang menghubungkan perusahaan, konsumen, dan komunitas tertentu melalui transaksi elektronik dan perdagangan barang, pelayanan, dan informasi yang dilakukan secara elektronik.

Dengan demikian, dapat disimpulkan bahwa Ecommerce merupakan proses pembelian dan penjualan jasa atau produk antara dua belah pihak melalui internet (commerce net) dan sejenis 
mekanisme bisnis elektronik dengan fokus pada transaksi bisnis berbasis individu dengan menggunakan internet sebagai media pertukaran barang atau jasa baik antar instansi atau individu dengan instansi.

\subsection{MySQL}

MySQL adalah database yang cepat dan tangguh, sangat cocok jika digabungkan dengan PHP, dengan database kita bisa menyimpan, mencari dan mengklasifikasikan data dengan lebih akurat dan professional. MySQL penggunakan SQL language (Structur Query Language) artinya MySQL penggunakan query atau bahasa pemprogaman yang sudah standar di dalam dunia database (Fathur Rohman, 2010).

MySQL termasuk jenis RDBMS (Relational Database Management Sistem). Sehingga istilah seperti tabel, baris dan kolom tetap digunakan dalam MySQL. Pada MySQL sebuah databasemengandung beberapa tabel, table terdiri dari sejumlah baris dan kolom.

Dalam konteks bahasa $S Q L$, pada umumnya informasi tersimpan dalam tabeltabel yang secara logik merupakan struktur dua dimensi. Tabel-tabel itu terdiri atas baris-baris data (row atau record) yang berada dalam satu atau lebih kolom. Baris pada tabel sering disebut sebagai instance dari kata sedangkan kolom sering disebut sebagai attributes atau field.

\subsection{PHP}

PHP merupakan script yang menyatu dengan HTML dan berada pada server (server side HTML embedded scripting). Dengan PHP ini Anda dapat membuat beragam aplikasi berbasis web, mulai dari halaman web yang sederhana sampai aplikasi komplek yang membutuhkan koneksi ke database.

PHP adalah singkatan dari "PHP: Hypertext Preprocessor", yang merupakan sebuah bahasa cripting yang terpasang pada HTML. Sebagian besar sintak mirip dengan bahasaC, Java dan Perl, ditambah beberapa fungsi PHP yang spesifik. Tujuan utama penggunaan bahasa ini adalah untuk memungkinkan perancang web menulis halaman web dinamik dengan cepat.

a. Program php harus di terjemahkan oleh webserver sehingga menghasilkan kode html yang dikirim ke browser agar dapat ditampilkan. Program ini dapat berdiri sendiri atau pun disisipkan diantara kode-kode html sehingga dapat langsung ditampilkan bersama dengan kode-kode html tersebutb File html yang telah dibubuhi program php harus diganti ekstensinya menjadi .php3 atau.php.

b. Versi terbaru, yaitu PHP 4.0 keluar pada tanggal 22 Mei 2000 merupakan versi yang lebih lengkap lagi dibandingkan dengan versi sebelumnya.

c. Tujuan dari bahasa scripting ini adalah untuk membuat aplikasi-aplikasi yang dijalankan di atas teknologi web. Dalamhal ini, aplikasi pada umumnya akan memberikan hasil pada web browser, tetapi prosesnya secara keseluruhan dijalankan web server.

d. Kekuatan yang paling utama PHP adalah ada konektivitasnya dengan system database di dalam web. Sistem database yang dapat didukung oleh PHP adalah: Oracle, MySQL, Sybase, PostgreSQL, dan lainnya

e. PHP dapat berjalan diberbaga system operasi seperti windows 98/NT, UNIX/LINUX, solaris maupun macintosh.

f. Keunggulan lainnya dari PHP adalah bahwa PHP juga mendukung komunikasi dengan layanan seperti protocol IMAP, SNMP, NNTP, POP3 dan bahkan HTTP.

\subsection{Definisi Penjualan}

Penjualan adalah suatu sistem keseluruhan dari kegiatan usaha yang ditujukan untuk merencanakan, menentukan harga, mempromosikan dan mendistribusikan barang, jasa, ide kepada pasar sasaran agar dapat mencapai tujuan organisasi (Bayu Swastha, 1989). Menurut Marwan (1991) penjualan adalah suatu usaha yang terpadu untuk mengembangkan rencanarencana strategis yang diarahkan pada usaha pemuasan kebutuhan dan keinginan pembeli, guna mendapatkan penjualan yang menghasilkan 1

\subsection{Definisi Internet}

stilah internet berasal dari bahasa latin, inter yang berarti "antara". Secara kata per kata internet berarti jaringan antara atau penghubung. Memang itulah fungsinya, internet menghubungkan berbagai jaringan yang tidak saling bergantungan pada satu sama lain dengan sedemikian rupa sehingga mereka dapat berkomunikasi. Internet adalah jaringan komputer yang saling terhubung 
keseluruh dunia tanpa mengenal batasan teritorial, hukum dan budaya.

Menurut Lani Sudharto (1996) walaupun secara fisik internet adalah inter koneksi antar jaringan komputer namun secara umum internet harus dipandang sebagai sumber daya informasi. Protocol TCP/IP menyatukan bahasa dan kode berbagai komputer didunia sehingga menjadi standart utama jaringan komputer. TCP/IP berkembang cepat dan kaya fasilitas karena bersifat terbuka dan bebas digunakan, ditambahkan kemampuan baru oleh siapapun dan gratis karena tidak dimiliki siapapun. Oleh karena itu, hingga saat ini jaringan-jaringan tersebut saling terhubung di seluruh belahan dunia.

\section{ANALISIS DAN PERANCANGAN SISTEM}

\subsection{Analisis Sistem}

Untuk menunjang pembuatan aplikasi web untuk mengakses pemasaran produk dibutuhkan beberapa komponen perangkat keras (hardware), perangkat lunak (software) dan brainware.

\subsubsection{Hardware}

Hardware adalah perangkat fisik yang menyusun sebuah komputer dan ikut memungkinkan komputer bekerja. Perangkat keras atau spesifikasi minimal hardware yang diperlukan terdiri dari :

- Processor Intel Core 2 Duo T5800 (2. 0 Ghz) atau yang setara

- Hardisk $250 \mathrm{~Gb}$

- RAM 2 GB DDR2

- Monitor Wide Screen dengan aspect ratio 16:10 atau 16:9

- Keyboard

- Mouse

\subsubsection{Software}

Software adalah perangkat yang memungkinkan komputer mengerjakan perintah perintah yang kita berikan. Software yang diperlukan oleh peneliti adalah sebagai berikut :

- Sistem Operasi (OS) Windows XP SP2

- Mozilla Firefox

- MySQL (XAMPP)

- PHP (Macromedia Dreamwevear 8)

\subsubsection{Brainware}

Brainware adalah orang yang bekerja dalam suatu sistem komputerisasi. Sistem baru membutuhkan orang yang menguasai aplikasi komputer yang akan menjalankan operai sehari hari, mulai dari menghidupkan komputer, menjalankan program, mencetak hasil pengolahan data dan melakukan perawatan komputer secara rutin. Dalam hal ini brainware adalah pengguna aplikasi (user) atau masyarakat umum.

\subsection{Perancangan Sistem}

Perancangan Sistem pada aplikasi Toko Minak Singa ini bertujuan untuk memberikan gambaran untuk mengidentifikasi komponen yang akan di desain. Tahap desain sistem secara umum dilakukan setelah tahap analisa selesai dilakukan Desain Sistem pada aplikasi.

\subsubsection{DFD (Data Flow Diagram)}

Diagram konteks adalah arus data yang berfungsi untuk menggambarkan keterkaitan aliran-aliran data antara sistem dengan bagian-bagian luar. Pada sistem yang dibuat pada Toko Minak Singa terdapat empat entitas yaitu Administrator yang mempunyai wewenang untuk mengelola control panel dan hak akses pada website. Customer melakukan pembelian pada produk, yang proses transaksinya dilakukan secara online, kemudian bagian gudang mempunyai tugas untuk mengecek ketersediaan barang. Manajer (Pemilik) menerima semua laporan data penjualan produk pada Toko Minak Singa. Gambar DFD dapat dilihat pada gambar berikut ini. 


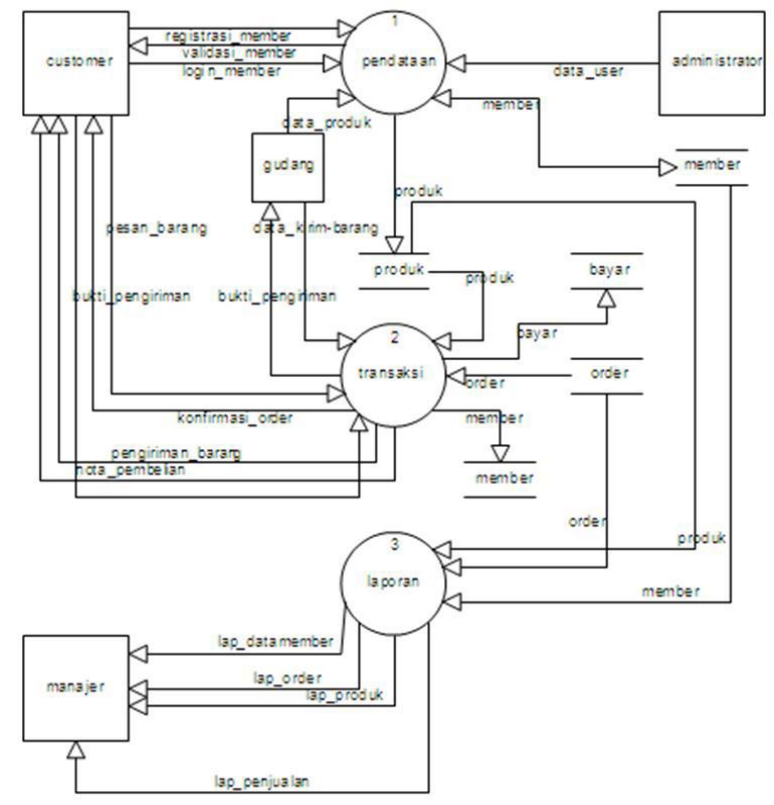

Gambar 3.1 DFD Level 1

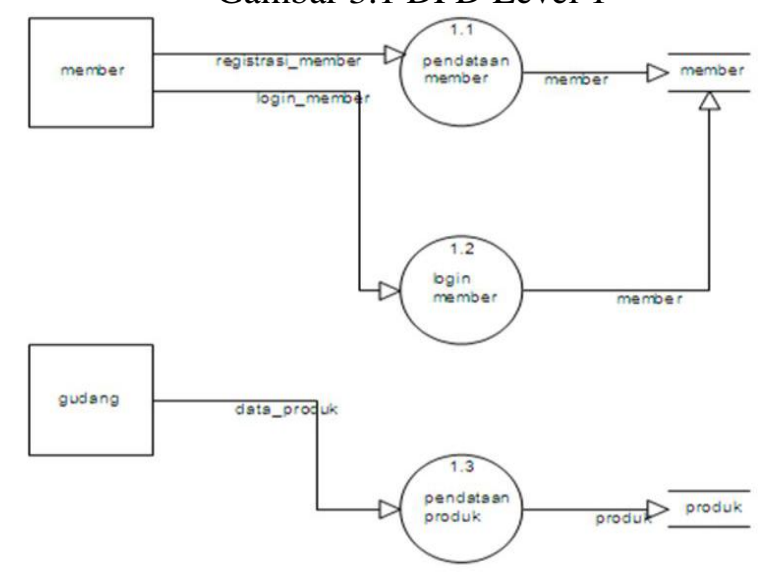

Gambar 3.2 DFD Level 2 Proses 1

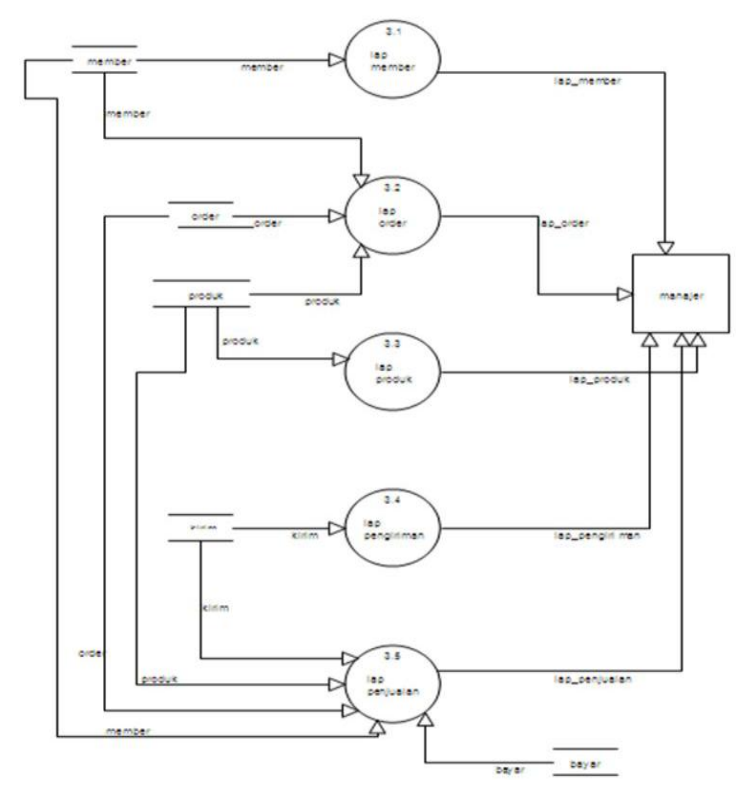

Gambar 3.3 DFD Level 2 Proses 2

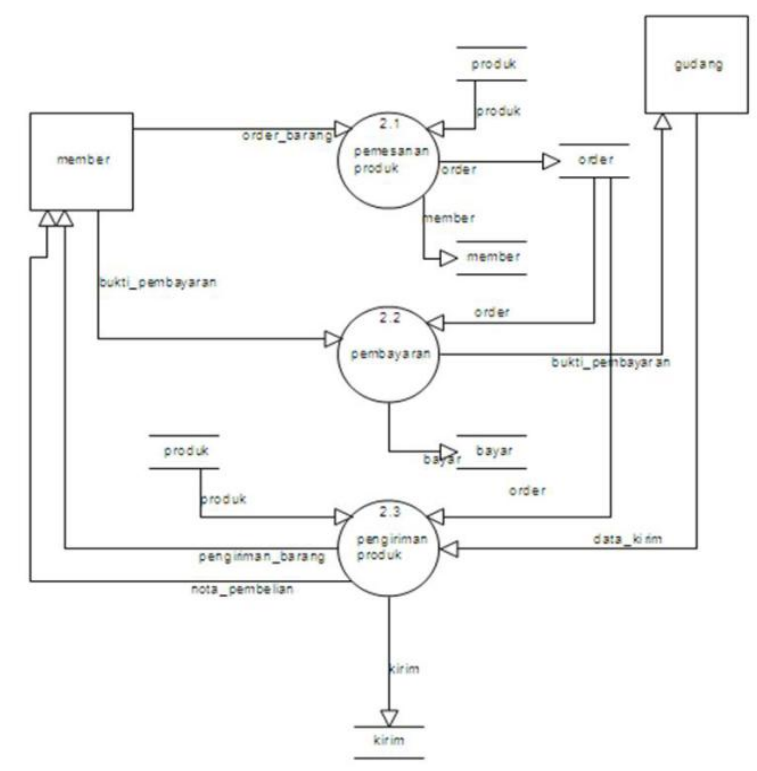

Gambar 3.4. DFD Level 2 Proses 3

\subsubsection{Entity Relationship Diagram}

ERD digunakan dalam membangun basis data untuk menggambarkan relasi atau hubungan dari dua file atau dua tabel. ERD terdiri dari 2 komponen utama yaitu entitas dan relasi. Kedua komponen tersebut dideskripsikan lebih jauh melalui atribut-atribut atau properti. Hubungan antar entitas yang terjadi dalam sistem ECommerce yang akan dirancang dapat dilihat pada Entity Relationship Diagram pada gambar 3.5.

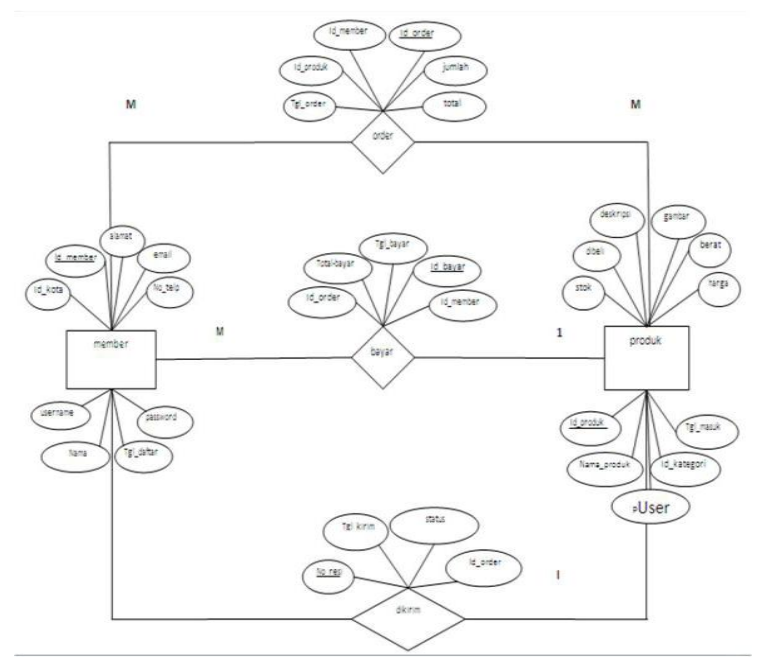

Gambar 3.5 Entity Relationship Diagram 


\section{DESAIN DAN IMPLEMANTASI SISTEM}

\subsection{Tampilan Halaman Utama}

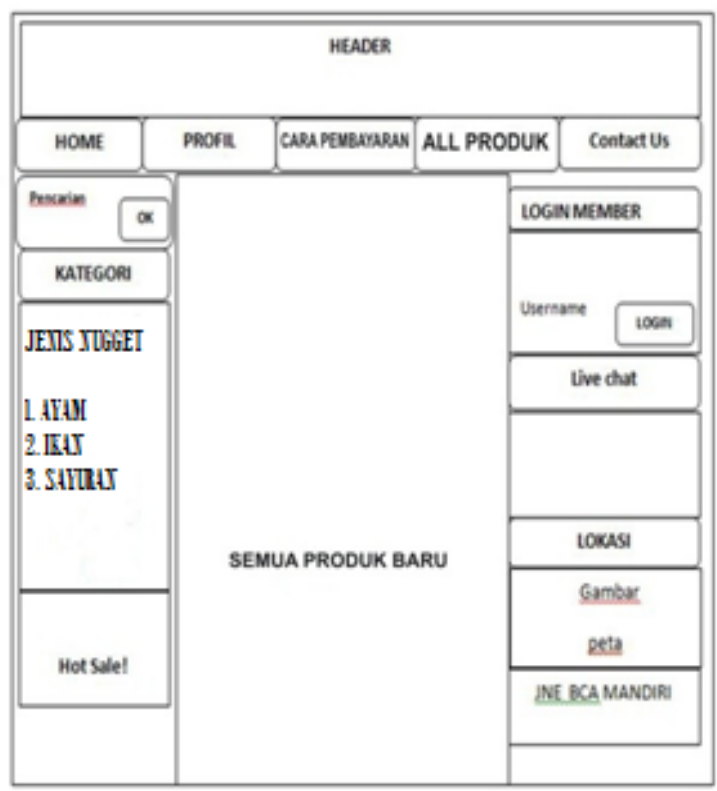

Gambar 4.1. Tampilan Halaman Utama

\subsection{Tampilan Cara Pembayaran}

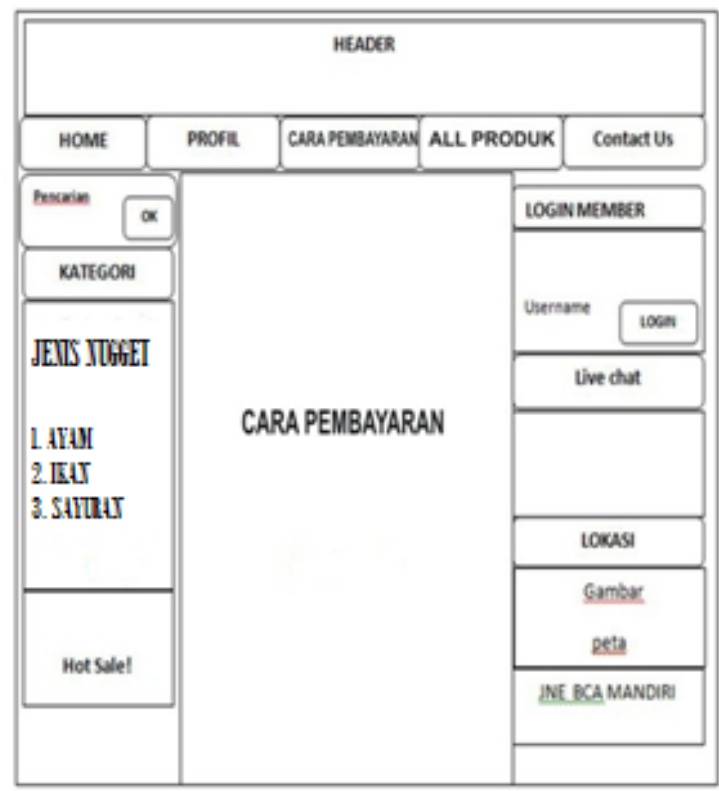

Gambar 4.2. Tampilan Cara Pembayaran

\subsection{Desain Tampilan Contact Us}

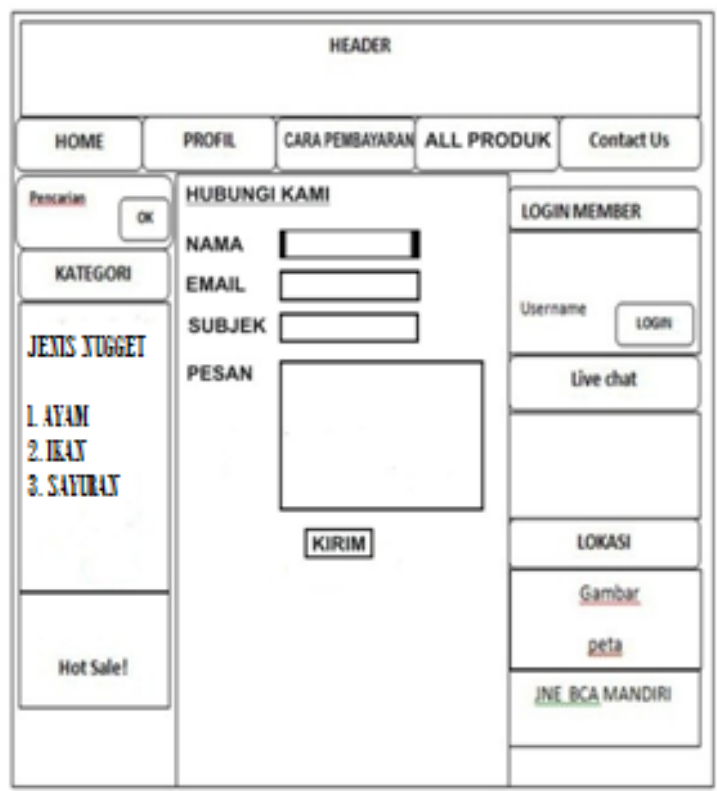

Gambar 4.3 Tampilan Contact Us

\subsection{Desain Tampilan All Produk}

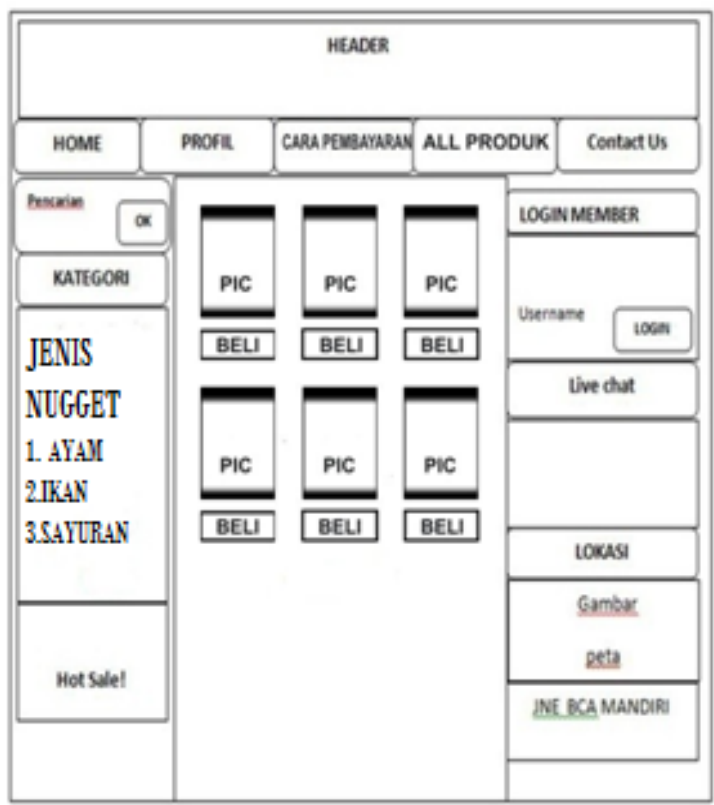

Gambar 4.4 Tampilan All Produk 


\subsection{Desain Tampilan Register Member}

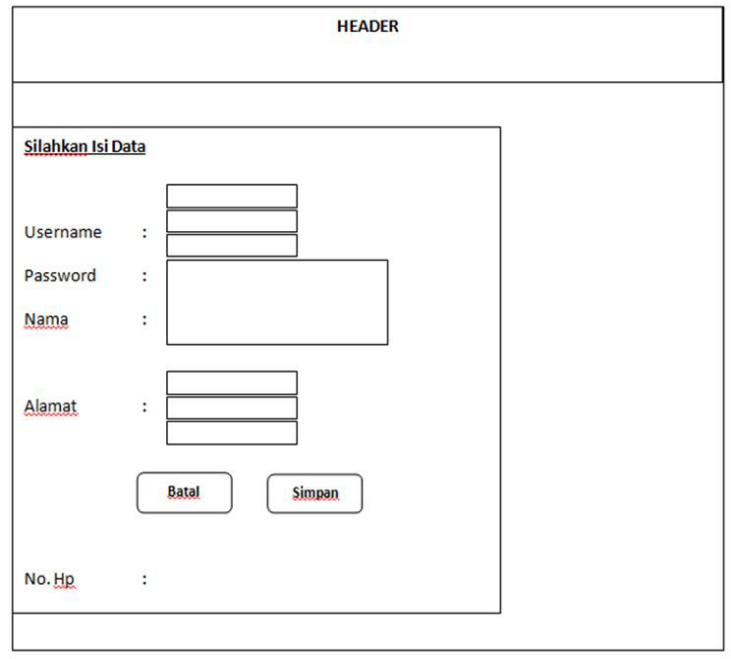

Gambar 4.5 Tampilan Register Member

\subsection{Desain Tampilan Halaman Login Member}

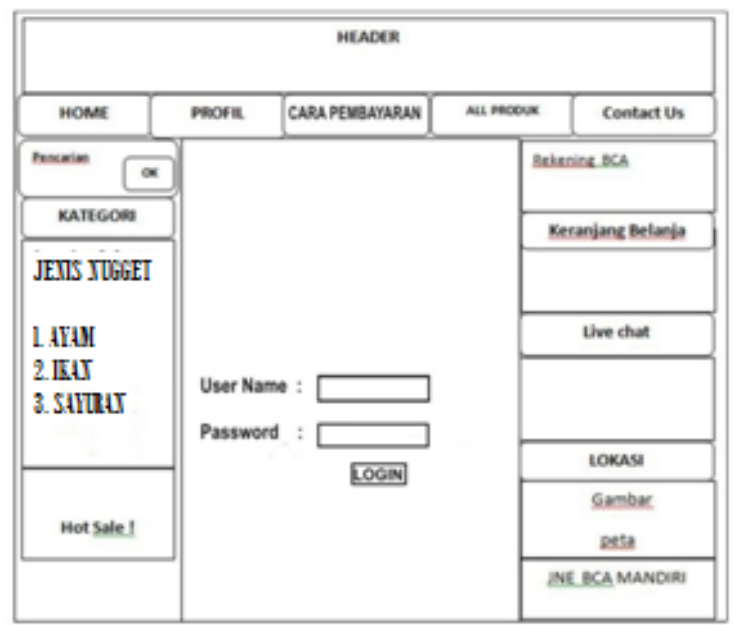

Gambar 4.6 Tampilan Halaman Login Member

\subsection{Tampilan Halaman Login Administrator}

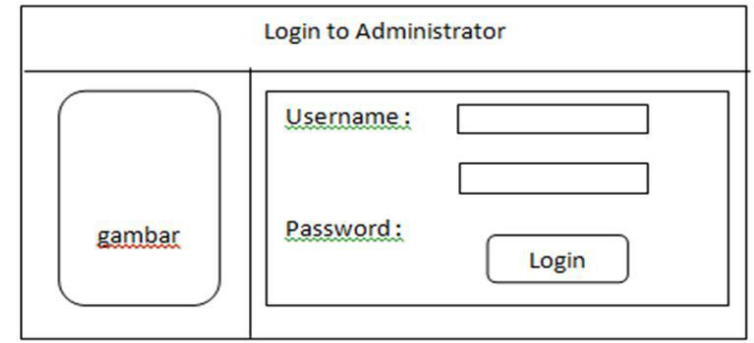

Gambar 4.7 Tampilan Halaman Login Administrator.

\subsection{Desain Tampilan Administrator}

"Pengaplikasian Sistem Penjualan pada Toko Minak Singa Berbasis E-Commerce" secara keseluruhan adalah sebagai berikut :

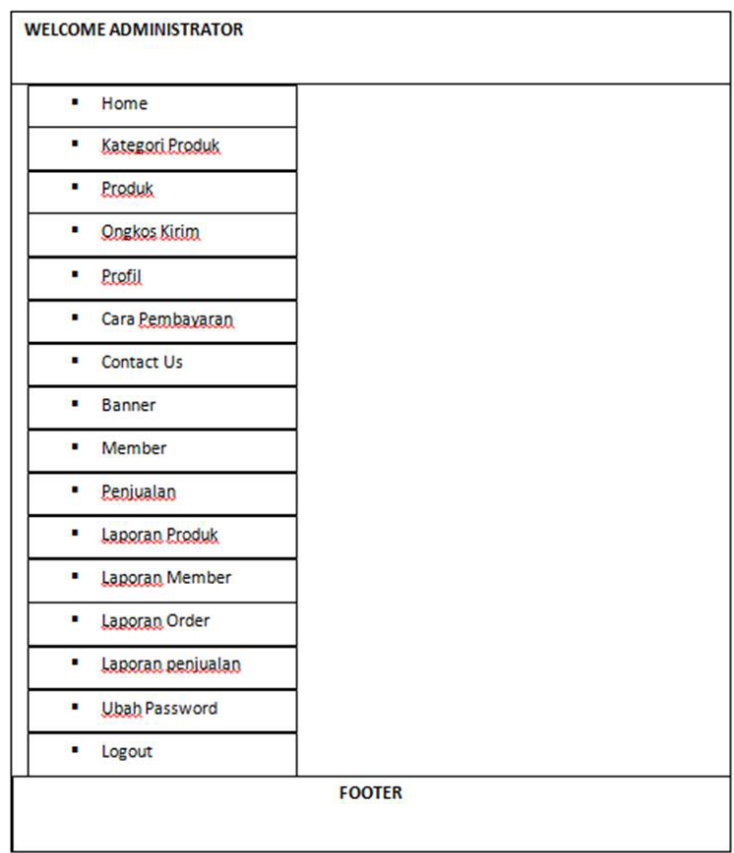

Gambar 4.8 Tam pilan Administrator

\section{PENUTUP}

\subsection{KESIMPULAN}

Kesimpulan dari penelitian ini sebagai berikut :

a. Aplikasi penjualan pada Toko Minak Singa berbasis E-commerce di rancang dengan menggunakan bahasa pemrograman PHP text editor, Macromedia Dremweaver, Adobe CS4 dan database MySQL. 
b. Adanya website pemasaran ini dapat membantu Toko Minak Singa dalam meningkatkan pelayanan dan penjualan di berbagai wilayah baik dalam kota maupun luar kota.

c. Aplikasi Penjualan Online pada Toko Minak Singa menyajikan laporan-laporan diantaranya laporan produk, laporan member, laporan order, dan laporan penjualan. Laporan-laporan tersebut ditujukan kepada pemilik sebagai bahan pertimbangan dalam perbaikan pelayanannya.

\subsection{SARAN}

Adapun saran dari penelitian ini sebagai berikut:

a. Diperlukan dukungan teknis yaitu berupa perangkat keras (hardware), kerangkat lunak (software) dan pemakai (brainware). Serta dukungan non teknis yaitu dukungan kedisiplinan para personil yang menangani sistem baru ini.

b. Diharapkan aplikasi E-commerce ini dapat diterapkan di Toko Minak Singa supaya meningkatkan penjualan.

\section{DAFTAR PUSTAKA}

[1] Bin Ladjamudin, AlBahra. (2005), Analisis dan Desain Sistem Informasi, Graha Ilmu, Yogyakarta.

[2] Jogiyanto, HM. (2005), Analisis dan Desain Sistem Informasi, ANDI Offset, Yogyakarta.

[3] Kurniawan, Heri. (2011), Trik Membuat Web Template dengan PHP \& CSS, Lokomedia, Yogyakarta.

[4] Kurniawan, Ruliyanto. (2008), Membangun Situs dengan PHP untuk Orang Awam, Maxikom, Palembang.

[5] Pressman, Roger S, Ph,D. (2002), Rekayasa Perangkat Lunak, ANDI Offset, Yogyakarta.
[6] Saputra, Agus. (2011), Membangun Aplikasi SMS dengan PHP dan MySQL, PT Elex Media Komputindo, Jakarta.

[7] Sarwono, Jonathan, Tutty. (2008), Teori ECommerce: Kunci Sukses Perdagangan di Internet, Gava Media, Yogyakarta

[8] Sidik, Bertha, Ir. (2005), MySQL Untuk Pengguna, Administrator, dan Pengembangan Aplikasi Web, Informatika, Bandung.

[9] Sunarto, Andi SEI. (2009), Seluk Beluk ECommerce, Garailmu, Jogjakarta.

[10] Swastika, Windra. (2005), Php 5 \&MySql 4, Proyek Shopping Chart 1, Dian Rakyat, Jakarta.

[11] Wahyudi, Bambang S. Kom, MMSi. (2008), Konsep Sistem Informasi, ANDI Offset, Yogyakarta. Url : http://blog. rosihanari. net http://en. wikipedia. org/ http://www.total. or. id http://www. ridwaniskandar. file. wordpress. Com

[12] Rara Sri Artati Rejeki (2011), Perancangan dan Pengaplikasian E-Commerce, Semarang 